\title{
DIREITO À SAÚDE: O PAPEL DE DIFERENTES SUJEITOS SOCIAIS NO EXERCÍCIO DA CIDADANIA*
}

\author{
Enly Catarina Moura
}

\begin{abstract}
Resumo: Além de poder refletir sobre a questão da cidadania e do poder institucional pretendo, neste trabalho, retratar as diferentes percepções que diferentes sujeitos sociais/institucionais, vinculados a uma unidade básica de saúde, têm sobre a saúde na perspectiva de contribuir para a consolidação do Sistema Único de Saúde (SUS), enquanto caminho para a Reforma Sanitária. Neste sentido, a teoria da problematização-ação foi aplicada à comunidade usuária do Centro de Saúde Escola Jardim Campos Eliseos, visando à eleição de determinadas ações para resolver parte dos problemas existentes. Este trabalho mostra que é possivel manter a luta contra-hegemônica na busca da igualdade social mesmo em cenários não favoráveis.
\end{abstract}

Palavras-chave: Direito à saúde; exercício de cidadania; teoria da problımatizaçãoação; percepção de sujeitos sociais/institucionais

\footnotetext{
*Trabalho desenvolvido junto à equipe do Centro de Saúde Escola Jardim Campos Eliseos, Faculdade de Ciências Médicas (FCM), Pontifícia Universidade Católica de Campinas (PUCCAMP), enquanıo coordenadora da unidade, e apresentado à disciplina Elementos Teóricos de Saúde e Sociedade I, Curso de Pós Graduação em Saúde Coletiva, Departamento de Medicina Preventiva e Social, FCM, Universidade Estadual de Campinas (UNICAMP), 1992.

**Nutricionista-Sanitarista, Mestre em Ciência da Nutrição, Doutora em Saúde Coletiva, Professora Titular do Departamento de Nutrição, FCM, PUCCAMP.
} 


\section{INTRODUÇÃO}

O direito, aqui, é entendido como um conjunto de normas e leis, que tem o objetivo de regula(menta)r as relações sociais entre pessoas, grupos, classes e instituições de uma determinada sociedade(L'ABBATE, 1990). Neste sentido, a luta contínua dos movimentos populares na busca do direito (de fato) à saúde tem se tornado instrumento eficiente de transformação do instituinte em direitos (de lei) sociais, tendo um importante papel na luta contra-hegemônica(COHN, 1991; L'ABBATE, 1990; SMEKE, 1989; TEIXEIRA, 1989). Assim, saúde enquanto direito de todos (e dever do Estado) não passa apenas pela questão legal, instituída na Constituição Brasileira de 1988(BRASIL, 1998), mas principalmente pela conquista social no sentido de garantir o cumprimento da lei.

Historicamente, a saúde enquanto direito é publicada pela primeira vez na Declaração Universal dos Direitos do Homem na Assembléia Geral das Nações Unidas, em 1948, onde o estado de bem estar é dado por uma série de direitos sociais (alimentação, moradia, vestimenta, assistência médica, serviços sociais e seguros sociais), além de trabalho e educação(MOURA, 1989).

Os direitos sociais, que englobam o direito à saúde, são decorrentes das conquistas dos direitos civis, no século XVIII, e políticos, no século XIX. Originalmente os direitos foram "permitidos" com o objetivo de manter a mesma estrutura social, isto é, a desigualdade social se mantinha mas a igualdade dos direitos era reconhecida, embora não exercida. Isto tinha o objetivo de reduzir coercitivamente os conflitos sociais entre grupos com interesses contrários. Este processo, no entanto, foi fundamental para que os direitos sociais fossem garantidos num patamar mínimo (estado de bem estar), o que permitiu a incorporação dos mesmos ao estado de cidadania, como fruto da luta contra a desigualdade, travada por grupos organizados da sociedade, o que caracteriza uma relação dialética instituinte/instituído 
(coersão/consenso) na medida em que o processo de conquista é dinâmico e contínuo (MOURA, 1989; TEIXEIRA, 1989).

O estado de bem estar, no Brasil, se aproxima mais do padrão meritocráticoparticularista(NEPP/NNICAMP, 1989). Assim, a marginalização inerente aos direitos mínimos, como ocorreu na Poor Law, se reproduz na maior parte do país onde a população, carente de serviços, se submete ao Estado numa relação de gratidão e não no exercício da cidadania. O Estado assume o seu papel conservador de proteção social ao "corrigir" algumas distorções do mercado, enquanto privilegia o modelo neo-liberal de assistência médica (BOLDSTEIN, 1990; MARSHALL, 1967).

A Constituição(BRASIL, 1988), por sua vez, assegura ao sujeito a garantia do exercício da cidadania, ao declarar o direito à saúde e considerar saúde como resultante de condições adequadas de moradia, alimentação, educação, renda, meio ambiente, lazer, trabalho, transporte, emprego, liberdade, posse da terra e acesso aos serviços de saúde. Assegura ainda a participação popular na gestão dos serviços de saúde. Utilizo, aqui, a conceituação de cidadania onde o indivíduo tem de fato a possibilidade de exercer seus direitos (civis, políticos e sociais) na busca da igualdade social.

É importante ressaltar a colaboração de diferentes atores sociais no desenvolvimento de uma consciência social, consequentemente sanitária, voltada aos direitos do cidadão. Participaram, como mediadores deste processo no Brasil, profissionais, políticos, militantes, os chamados "agentes externos", na busca do envolvimento popular na luta pela cidadania(JACOBI, 1989; RAMOS, 1989; SADER, 1988).

No caso da saúde, a instituição torna-se um local privilegiado da luta contrahegemônica ao possibilitar a expressão da cidadania(LUZ, 1979; RAMOS, 1989). Aqui, os "agentes externos" garantem o espaço de gestão. Segundo RAMOS e col.(1989) "a população, apesar de esmagada pelas condições de vida que enfrenta, emite suas propostas e representações, constituindo-se também como intelectuais portadores de saberes, mas 
sua ação de classe torna ainda mais débil o impacto que poderiam provocar no curso tomado pelas decisões administrativas". Ainda segundo os autores, a instituição é uma instância de reprodução social. No meu entender, a reprodução que se dá é a do discurso levado pelos agentes privilegiados e o impacto tão pequeno é devido à força que o governo tem dado ao modelo neo-liberal de assistência à saúde, que inclusive atrai parcela significativa dos profissionais da saúde. Mantém-se a relação dominantes-dominados (agentes privilegiados e subordinados), não só na dimensão estrutural e social internas mas também, contraditoriamente ao discurso contra-hegemônico da instituição, nas relações sociais externas(LUZ, 1979). Entretanto, entendo, que esta é uma das formas dos intelectuais da classe dominada se apropriarem do discurso contra-hegemônico na luta pela cidadania e assumirem a frente das reivindicações por justiça social, a exemplo do que vem acontecendo em diversos movimentos populares(JACOBI, 1989; PETRINI, 1984; SADEL, 1988; SMEKE, 1989). $O$ agente intelectual atua como legitimador e reprodutor do saber, o que o qualifica a decodificar os dizeres populares, enquanto mediador de um processo de transformação social(COSTA, 1989; REZENDE, 1989).

Segundo TESTA(1989), o diagnóstico em saúde pode ser dividido em quatro categorias: estado de saúde e situação epidemiológica, enquanto expressão direta do problema e suas causas, setor saúde e serviços prestados, enquanto formas organizativas, que podem ser analisadas do ponto de vista administrativo, estratégico e ideológico, respectivamente ligados ao setor saúde, às forças sociais em relação ao setor e às forças sociais em relação à totalidade social. Aqui, o diagnóstico administrativo dimensiona os recursos, quantifica os objetivos e os relaciona. O diagnóstico estratégico indica as mudanças necessárias e possíveis que possam afetar o poder do setor, sendo necessário explicitar as diferenças conforme o grupo social. $O$ diagnóstico ideológico permite identificar quais os grupos sociais que sustentam determinadas idéias quanto ao processo saúde-doença, fornecendo subsídios para a direção estratégica da legitimação da proposta de saúde que se tem.

O diagnóstico estratégico, incorporando diferentes atores sociais, torna-se um 
instrumento adequado à legitimação da Reforma Sanitária. A superação da dicotomia entre avaliação quantitativa e qualitativa remete obrigatoriamente a questão da avaliação do enfoque estratégico, onde o diagnóstico ideológico é o ponto de partida para o planejamento em saúde, dentro desta perspectiva (GOULART, 1990).

Mais recentemente, o enfoque estratégico tem sido considerado, por alguns autores(CECÍLIO, 1991; GAWRYSZEWSKI,1991; RIVERA, 1989; TAVEIRA, 1991), como um instrumento fundamental ao planejamento, enquanto discussão do poder de classes, na programação em saúde e, até mesmo, na consolidação do SUS.

A fim de entender como cada ator social apreende esta questão, aplicamos a técnica da problematização-ação (declaração do problema e definição das operações a serem desencadeadas para resolver o problema), tendo como referencial o pensamento estratégico(TESTA, 1989). Neste caso, os atores sociais envolvidos foram o sujeito coletivo (clientes, alunos, técnicos, e professores do Centro de Saúde Escola Jardim Campos Elíseos da Pontifícia Universidade Católica de Campinas - PUCCAMP), considerado como aquele que tem um projeto sobre o assunto, controla recursos e disputa a hegemonia com outros grupos; e personalidade notável (PUCCAMP, Prefeitura Municipal de Campinas) na medida em que detém recursos (político, financeiro, cognitivo, organizacional) e participam do mesmo "jogo social".

\section{METODOLOGIA}

O Centro de Saúde Escola Jardim Campos Elíseos da PUCCAMP, integrado à rede básica de saúde de Campinas, além de seu papel precípuo de formador de recursos humanos na área da saúde, presta assistência à saúde da população residente no bairro (cerca de 35 mil habitantes) que leva o seu nome com o objetivo de contribuir para a melhoria dos níveis de saúde por meio de práticas de promoção, preservação e recuperação da saúde. Visa, 
ainda, o desenvolvimento de novos modelos ou propostas voltadas à melhora da qualidade da assistência, administração, gerência e capacitação profissional.

Seu projeto se insere no projeto político-pedagógico da PUCCAMP, que tem como diretriz o compromisso social, determinado pelas necessidades da população, com opção pelo público.

O Centro de Saúde Escola Jardim Campos Elíseos contava, em 1992, com 4 auxiliares de saúde, 3 técnicos de enfermagem, 1 enfermeira supervisora, 2 pediatras, 2 clínicos, 5 docentes de medicina, 1 de fisioterapia, 1 de nutrição e 1 de ciências farmacêuticas, além de 6 acadêmicos de medicina, 5 de nutrição, 5 de fisioterapia e 2 de ciências farmacêuticas.

As atividades assistenciais eram realizadas na forma de atendimento individual $e$ coletivo nos programas de atençăo à saúde da criança, do adulto e da mulher, educação em saúde e vigilância epidemiológica, bem como em atendimentos de urgência, na unidade sanitária, nas escolas da sua área de cobertura e em visitas domiciliares, por meio da atividade docente-assistencial ou exclusivamente assistencial.

O gerenciamento era realizado pelo Conselho da Unidade, composto por todos os membros da equipe de trabalho e por representantes da população, e executado por um docente com formação em saúde pública/coletiva escolhido pela equipe. De acordo com a Lei Orgânica do Município de 02/06/91 a equipe participava do Conselho Local de Saúde (CLS).

Adotou-se como método de trabalho o diagnóstico estratégico situacional simplificado (problematização-ação), tendo como referencial teórico o pensamento estratégico de TESTA(1989), com a finalidade de planejar as ações de saúde para o segundo semestre de 1992. 
Foram considerados os seguintes atores institucionais: clientes, alunos, técnicos e professores.

Para cada ator social/institucional foi realizada uma dinâmica de grupo, onde cada sujeito deveria listar os problemas de saúde sentidos e, a partir daí, em pequenos grupos, discutir suas formas de explicação, ações a serem desenvolvidas no sentido de solucionálos e quais os recursos necessários para isto.

As reuniões ocorreram na seguinte ordem: clientes, alunos, técnicos e professores. Posteriormente, foi realizada uma nova reunião, com todos os profissionais prestadores de serviços da unidade de saúde, consequentemente decisores das ações(ALBUQUERQUE, 1978; ALBUQUERQUE \& RIBEIRO, 1979) a serem ali desenvolvidas, onde foram apresentadas as propostas dos grupos, anteriormente reunidos, e novo diagnóstico foi realizado, procurando situar o(s) responsável(is) pela(s) ação(ões).

\section{RESULTADOS}

\section{Os clientes}

A população do Jardim Campos Elíseos, desde o final da década de 70, luta por equipamentos sociais para a região. Como conquistas podem ser citadas a creche ligada à Sociedade de Amigos do Bairro, a Escola Estadual de Primeiro e Segundo Graus e o atual Centro de Saúde vinculado à PUCCAMP. Em 1992, lutava pela construção de um novo prédio para o Centro de Saúde.

Para este estudo foi realizada uma reunião com a Comissão Popular de Saúde da região, que contou com a participação ampla e aberta da/à população da área.

Como problemas de saúde foram citados a violência, o alcoolismo, a drogadição, a 
hipertensão arterial, a fome, a bronquite, o derrame, o nervosismo, a escolaridade critica: $A$ fim de evitar o reducionismo próprio da simplificação que fiz da problematização elaborada pela população, cito dois exemplos literais:

"O maior problema é a correria do dia a dia que acaba com pressão alta. Derrame nervosismo bebidas"

"O maior problema que eu vejo aqui no bairro e muita gente com bronquite principalmente criança e problema de pressão"

A explicação para estes problemas é muito rica: violência na televisão e na própria família, desunião da família, desvalorização das pessoas, desespero, descrença, desemprego, salários baixos, nervoso, crise econômica, desestruturação da sociedade tendo como exemplo o governo. Aqui, exemplifico com:

"A violência é gerada na própria familia por falta de endendimento na falta de salário justo na falta de governantes justos"

"A crise econômica esta tão defasada que provoca o baixo salário e esse provoca a fome e a fome provoca as enfermidades"

A população considerou que estes problemas poderiam ser resolvidos com as seguintes operações: participação no gerenciamento da escola, divulgação de informações verdadeiras, organização popular e apoio a movimentos por melhores condições de vida, valorização das pessoas, transparência do executivo, exercício da cidadania, conscientização, desenvolvimento de uma sociedade socialista, bom atendimento médico, política econômica adequada.

\section{Exemplos:}

"Para amenizar os problemas na saúde nos precisamos ter um bom atendimento medico, e ter uma política econômica adequada"

"Para resolver esses problema teria um salário digno e os governadores ajudar a população com melhor atendimento medico e alimentação melhor o custo de vida do dia a dia no transporte" 
Como recursos necessários foram relacionados: profissionais competentes, com conhecimentos gerais, capacitados à defesa da vida, equipamentos abertos a intervenção popular, meio de informação a serviço da defesa da vida, garantia de direitos básicos de cidadania, redistribuição do orçamento com priorização das áreas sociais (educação e saúde), reforma agrária autêntica, organização e pressão popular, repasse das verbas da saúde para as unidades básicas, aumento dos profissionais e espaço adequado para o atendimento em saúde. Exemplos:

"Precisamos organização, muita luta e coragem de enfrentar os govemantes"

"O Govemo Federal tem que repassar as verbas destinadas a área da saúde ao governo do estado e governo do estado passar ao governo municipal e o govemo municipal ampliar todos os postos de saúde e facilitar o transporte"

"Seria mais recurso com lugar adequado com espaço suficiente melhores verba repassada para os postos do Governo do Estado para as Prefeitura para manter os custo suficiente".

\section{Os alunos}

O Centro de Saúde Escola Jardim Campos Elíseos oferecia, em 1992, estágios aos alunos da graduação dos Cursos de Ciências Farmacêuticas, Fisioterapia, Medicina e Nutrição.

Os alunos, enquanto atividade pedagógica, se reuniram para desenvolver o planejamento. Elegeram os seguintes problemas: espaço físico inadequado para as atividades a serem desenvolvidas, falta de integração acadêmico-profissional, falta de medicamentos básicos e demora na entrega de resultados de exames. $O$ alto número de pessoal acadêmico (professores e alunos) em relação ao espaço físico, a adaptação de uma residência de bairro periférico para tornar-se uma unidade de saúde, a falta de organização (referência e contra- 
referência) nos encaminhamentos entre os cursos, a não garantia de abastecimento de medicamentos e a demora ou extravio de resultados de exame por parte dos laboratórios da Faculdade de Ciências Médicas (FCM) e do Hospital e Maternidade Celso Pierro (HMCP), ligados à PUCCAMP, foram utilizados para explicar os problemas citados. Como operação citaram a construção de um novo Centro de Saúde, a reorganização de cima para baixo para garantir a referência e contra-referência e padronização de medicamentos, a entrega periódica de medicamentos e resultados de exame, a garantia de uma fonte de abastecimento. Neste momento, discuti com os alunos que a construção de um prédio não era de nosso domínio, enquanto ator social, mas sim a pressão para garantir a construção. Neste caso a operação seria pressão junto à Secretaria da Saúde e Reitoria da Universidade. Para a integração entre os cursos, a meu ver, a forma adequada seria o desenvolvimento de atividades conjuntas e não organizar de cima para baixo. Quanto a garantia de abastecimento de medicamentos propus pressão no sentido da compra de medicamentos com a verba do SUDS (Sistema Unificado e Descentralizado de Saúde), recebida pela PUCCAMP, e compromisso da Secretaria da Saúde com o abastecimento local.

Dando continuidade à atividade, os alunos elegeram como recursos, para a resolução destes problemas: informação à imprensa sobre o atraso das obras da nova unidade, realização de atos públicos de protesto, celebração de convênio entre a Universidade e a Prefeitura, integração docente, socialização das informações para os alunos, formação de grupos específicos para o trabalho integrado (hipertensos, obesos, diabéticos, gestantes, ...), solicitação junto à administração superior da PUCCAMP de uma maior integração entre as unidades básicas de saúde e o HMCP.

\section{Os técnicos}

Neste grupo participaram os auxiliares de saúde e os técnicos de enfermagem; a enfermeira supervisora e os médicos assistenciais. Cabe ressaltar que entre os médicos, esteve presente o tempo todo uma clínica geral, que exercia também a docência e que já 
tinha um conhecimento formal da técnica empregada, o que ajudou na elaboração da planilha. Os demais participaram pontualmente conforme suas disponibilidades de horários.

Os técnicos sistematizaram os problemas em três grupos principais: infra-estrutura deficiente (espaço físico inadequado, falta de equipamentos, medicamentos e material de trabalho em geral), recursos humanos precários (insuficientes e inadequados), e repressão da demanda. As explicações para estes problemas foram: a adaptação de um imóvel residencial para unidade de saúde, o planejamento não é obedecido na Universidade (falta de previsão, processo de compras lento, retaguarda administrativa falha), a verba SUDS insuficiente para a compra de medicamentos e o não envio rotineiro de medicamentos por parte da Secretaria de Saúde para infra-estrutura deficiente; o quadro funcional limitado pela Universidade, os baixos salários, falta de apoio à capacitação e falta de momentos comuns (treinamento, seminários, discussão de condutas) para recursos humanos precários; agendamento de consultas médicas não cumprido, falta de cumprimento do horário por parte de alguns médicos e de outros profissionais e, principalmente, falta de pessoal e espaço físico inadequado para repressão de demanda; além da falta de vontade política das instituições envolvidas (Universidade e Prefeitura) em priorizar a saúde, o que foi considerado o nó crítico de quase todos os problemas listados. Foram definidas as seguintes operações: pressão junto à Secretaria da Saúde para a conclusão do novo prédio, ampliação do quadro pessoal por parte da Secretaria da Saúde, retomada das negociações sobre fornecimento de medicamentos com a Secretaria da Saúde, agilização do funcionamento do Conselho da Unidade, realização de seminários técnicos, pressão junto à PUCCAMP para implantar política de capacitação adequada, normatização do agendamento de consultas e atendimento de emergência, registro do não cumprimento do horário e encaminhamento do diagnóstico situacional para instâncias superiores. Os recursos listados foram político, organizacional $e$ cognitivo para os três grandes blocos de problemas, na medida em que este ator não domina os recursos financeiros, o que gera o nó crítico e demandas para os outros atores envolvidos (personalidades notáveis). 


\section{Os professores}

A docência-assistência no Centro de Saúde Escola Jardim Campos Elíseos se dá de forma multiprofissional, interdisciplinar, fundamentada no instrumental epidemiológico e integrada à rede municipal de saúde. $O$ campo de atuação é a saúde coletiva, enquanto método de abordagem do processo saúde-doença, dentro das diretrizes do SUS. Aos docentes, também, cabem a administração especíica, o planejamento e a operacionalização, por meio da assistência e da pesquisa, dos serviços do Centro de Saúde.

quadro docente da unidade era composto, em 1992, por 1 farmacêutica, 1 fisioterapeuta, 5 médicos e 1 nutricionista, os dois últimos grupos com formação em Saúde Publica/Coletiva.

Após a listagem dos problemas, os docentes identificaram 3 grandes níveis de explicação, a saber: falta de priorização governamental e da própria Universidade para explicar o espaço pequeno/inadequado e a falta de equipamentos básicos e recursos humanos; recursos humanos precários (não ampliação das horas dedicação para os professores horistas, não clareza do perfil docente em saúde coletiva na contratação, falta de capacitação em saúde coletiva, falta de compromisso/conscientização com o projeto de saúde coletiva) para explicar o não cumprimento do horário, a falta de respeito profissional, a falta de integração, a indefinição do papel docente na equipe, a sobrecarga de trabalho para alguns docentes; $e$ apoio governamental ao modelo neo-liberal/descompromisso com o SUS para explicar a falta de integração entre o HMCP e a rede básica de saúde. Operações citadas: acompanhamento das negociações e pressão junto à Universidade e Prefeitura, participação dos eventos políticos e técnicos da área, participação do Plano Diretor junto à Universidade para o primeiro bloco; definição de critérios de contratação, controle de horário, dinâmicas de grupo, seminários técnicos, priorização de projetos de integração, pressão junto a Universidade para oferecer cursos na área, divulgação do trabalho desenvolvido na unidade para o segundo bloco; e 
estimulo ao projeto de integração junto ao HMCP para o terceiro bloco. Recursos necessários: político, organizacional e cognitivo em todos os blocos. Da mesma maneira que os técnicos, os docentes não detêm os recursos financeiros, gerando demandas para outros atores.

\section{A unidade de saúde}

Na reunião conjunta dos profissionais que atuam na unidade considerou-se que o ator coletivo (Centro de Saúde Escola Jardim Campos Elíseos) detém recursos político, cognitivo, organizacional e até financeiro, considerando o orçamento indireto a que faz jus pela Universidade e o repasse do SUDS.

Como imagem-objeto foram citados espaço físico adequado, recursos humanos e materiais suficientes, atendimento de boa qualidade e adequado às necessidades da população, alta resolutividade, aumento do índice de atendimento da área de cobertura, integração entre as diferentes áreas, com a população e com outros níveis de atenção, privilégio das ações de promoção e proteção da saúde, treinamento e formação de recursos humanos, profissionais motivados para o trabalho em saúde coletiva, campo para pesquisa em saúde e participação popular na gestão da unidade a fim de contribuir para o desenvolvimento de sujeitos sociais e melhores condições de vida e saúde.

Identificaram-se vários atores envolvidos com o problema: PUCCAMP (Reitoria, ViceReitoria para Assuntos Administrativos), Prefeitura Municipal de Campinas, Secretaria Municipal da Saúde, Faculdade de Ciências Médicas (Direção, Departamentos), usuários (alunos, Comissão Popular de Saúde), Conselho Local de Saúde, Secretaria Estadual da Saúde, Governo Federal, outros serviços de saúde (medicina de grupo, filantrópicos, autônomos, farmácias), associações e sindicatos profissionais (Associação e Sindicato dos Professores da PUCCAMP, dos Funcionários da PUCCAMP, dos Servidores Municipais), vereadores e deputados. 
O grupo concluiu que há uma relação constante de troca entre os diferentes níveis de interferência (Centro de Saúde, desinteresse da instituição - PUCCAMP, desenvolvimento histórico político valorizador da dominação como núcleo das relações sociais - ideologia), um(s) atuando sobre o(s) outro(s) e modificando seus saberes, seus discursos, suas posturas, num processo dialético instituinte/instituído que possibilita, no entender da equipe, a luta contra-hegemônica a favor da igualdade social.

A matriz básica do planejamento da unidade priorizou alguns dos problemas citados, como segue: repressão de demanda, espaço físico inadequado, falta de equipamentos, falta de medicamentos, recursos humanos inadequados, integração deficiente, falta de motivação para o trabalho, descompromisso do profissional com o projeto de saúde coletiva e sobrecarga de funções. As ações eleitas foram as seguintes: pressionar Prefeitura para entregar a nova unidade, negociar abastecimento de medicamentos com a Secretaria Municipal de Saúde, normatizar ações de saúde, principalmente em condutas conflitantes, promover seminários e encontros de lazer, embelezar o atual espaço físico, trazer outros profissionais para palestras na unidade, estimular criatividade individual, incrementar a participação nas entidades de classe, cumprir horário, reformular agendamento, contratar recursos humanos para nova unidade, sensibilizar para a criação de uma carreira funcional, definir perfil docente em saúde coletiva, pressionar PUCCAMP para capacitação docente/funcional e criação do Colegiado da Rede Básica, retomar seminário da Rede Básica, encaminhar denúncias contra HMCP, encaminhar este diagnóstico para administração superior, solicitar reuniões com todos os envolvidos diretamente (Bispo, HMCP, Secretaria da Saúde, FCM, Departamento de Medicina Social e Preventiva). Definiram-se os responsáveis por algumas operações. Outras ficaram em aberto, aguardando a possibilidade de ação na medida em que a equipe é pequena e um dos problemas citados é a sobrecarga de tarefas.

Uma questão importante que sintetiza toda a problemática merece ser citada: como ser um centro de saúde escola nestas condições? 


\section{DISCUSSÃO E CONCLUSÕES}

Segundo CAMPOS(1991), a gestão, enquanto instrumento de poder, tem um papel estratégico na implantação do SUS, ao se tornar permeável à influência dos diversos atores sociais envolvidos. A definição de objetivos estratégicos e suas formas de consecução, segundo o autor, garantem a democratização dos instrumentos de gerência e a gestão coletiva dos serviços de saúde.

Um exemplo de como atuar pode ser extraído da avaliação dos alunos. A visão dos alunos é muito técnica e extremamente linear. A maioria encontra-se por volta do quarto/ quinto ano de faculdade, o que revela o limite da formação quanto a determinação da processo saúde/doença. Retoma-șe.a questão "como ser um centro de saúde escola nestas conidições?" Aos professores de saúde coletiva cabe a responsabilidade de desenvolver este assunto a partir do primeiro ano de faculdade, no entanto o currículo das escolas de saúde também reproduz a hegemonia vigente. $A$ equipe de profissionais da unidade, enquanto agente privilegiado, por deter o poder, a legitimação sobre o objeto, o saber(ALBUQUERQUE, 1978; ALBUQUERQUE \& RIBEIRO, 1979), tem um papel importante na condução deste processo.

Neste trabalho, o modelo adotado permitiu observar a percepção que os diferentes atores têm da saúde, onde a população, na luta pelo atendimento de suas expectativas e necessidades, exerce o seu "status" de cidadania, num processo político amplo e democrático, além de favorecer a compreensão, por parte da equipe de saúde, dos problemas de saúde sentidos. Os "erros" de gramática e de concordância por parte da população não são impedimentos para a compreensão da clara percepção que tem sobre a saúde. Situam os problemas ao nivel da política geral do país, como pode ser observado, e entendem que a solução passa por uma transformação social ampla.

Para COHN e col.(1991), a explicitação das representações que a sociedade tem sobre a questão da saúde, e da vida de uma forma geral, são fundamentais para a instituição dos direitos, na medida em que evidencia as desigualdades sociais existentes. 
MINAYO e SOUZA(1989), a partir da análise da representação social da saúdedoença, de uma comunidade, propõem aos planejadores em saúde que garantam a participação popular como ponto básico na consecução de um sistema de saúde voltado às reais necessidades da população. BERLINGUER(1988), por sua vez, questiona o papel dos administradores das instituições de saúde e a forma de avaliação da pequena participação popular.

A participação popular junto ao Centro de Saúde Escola Jardim Campos Elíseos, articulada ao compromisso docente-assistencial da equipe de permeabilidade e estímulo a integração com a comunidade usuária, permitiu a institucionalização do CLS desde 20/05/ 91, conforme determinado em lei municipal. Assim o processo instituinte/instituído, referente ao controle social, se efetivou após uma luta de cerca de dez anos. Por outro lado, o processo se mantém pois a simples oficialização do direito não é, ainda, garantia de seu exercício. A participação popular na gestão da unidade ainda é incipiente, tímida. O controle social na gestão dos serviços de saúde ainda é bastante frágil. Assim, é fundamental estimular a participação popular nos diferentes níveis de gestão, assegurando-lhe o controle social sobre o Estado.

Segundo SADER(1988), novos atores sociais, sujeitos coletivos com visibilidade pública, emergem das lutas populares e operárias na reivindicação de seus direitos por melhores condições de vida e trabalho. A população organizada do Jardim Campos Elíseos é um exemplo disto, como pode ser visto por seus discursos sobre a saúde .

\section{REFERÊNCIAS BIBLIOGRÁFICAS}

ALBUQUERQUE, J.A.G. Metáforas da desordem. Rio de Janeiro, Paz e Terra, 1978. p.6980: Elementos para uma análise da prática institucional. 
ALBUQUERQUE, J.A.G. \& RIBEIRO, A.E. Da assistência à disciplina: o programa de saúde comunitária. São Paulo, USP, 1979. [mimeografado]

BERLINGUER, G. Os direitos do doente. In: BERLINGUER, G. et al. Reforma sanitária: Itália e Brasil. São Paulo, Hucitec/CEBES, 1988. p. 132-56.

BOLDSTEIN, R.C.A. Estado de bem-estar social e cidadania: questões para o debate sobre políticas sociais. Saúde em Debate (30):21-5, 1990.

BRASIL. Constituição, 1988. Constituição da República Federativa do Brasil. São Paulo. Imprensa Oficial do Estado, 1988.

CAMPOS, G.W.S. A saúde pública e a defesa da vida. São Paulo, Hucitec, 1991. p.107-27: A gestão enquanto componente estratégico para a implantação de um sistema público de saúde.

CECÍLIO, L. A construção de uma cultura institucional de planejamento: contribuição do município. Saúde em Debate. (31):67-72, 1991.

COHN, A. et al. A saúde como direito e como serviço. São Paulo, Cortez, 1991.

COSTA, N.R. Transição e movimentos sociais: contribuição ao debate da reforma sanitária. In: COSTA, N. R. et al. Demandas populares, políticas públicas e saúde. Petrópolis, Vozes, 1989, Vol. I, p.45-66.

GAWRYSZEWSKI, V. O sistema de planejamento e seus métodos nos serviços de saúde do estado do Rio de Janeiro. Saúde em Debate. (32):43-7, 1991.

GOULART, F. A. A. Construção local do modelo assistencial de saúde, a luz do planejamento estratégico. Saúde em Debate. (28):56-9, 1990. 
JACOBI, P. R. Movimentos Sociais e Estado: efeitos político-institucionais da ação coletiva. In: COSTA, N. R. et al. Demandas populares, politicas públicas e saúde. Petrópolis, Vozes, 1989, Vol. 2, p.13-35.

L'ABBATE, S. O direito à saúde: da reivindicação à realização. Projetos de política de saúde em Campinas. São Paulo, 1990. [Tese de Doutorado apresentada à FFLCH-USP]

LUZ, M. As instituições médicas no Brasil. Rio de Janeiro. Graal, 1979. p. 23-47: Estratégia de hegemonia e análise política de instituições.

MARSHALL, T. H. Cidadania, classe social e status. Rio de Janeiro, Zahar, 1967. p.57-114: Cidadania e classe social.

MINAYO, M. C. S. \& SOUZA, H. O. Na dor do corpo, o grito da vida. In: COSTA, N. R. et al. Demandas populares, políticas públicas e saúde. Petrópolis, Vozes, 1989, Vol. 2, p.75101.

MOURA, D. Saúde não se dá: conquista-se. São Paulo, Hucitec, 1989.

NEPP/UNICAMP. Brasil 1987. Relatório sobre a situação social do país. Campinas, UNICAMP, 1989.

PETRINI, J. C. CEB's: um novo sujeito popular. Rio de Janeiro, Paz e Terra, 1984.

RAMOS, C. L. et al. Quem educa quem? Repensando a relação médico-paciente. In: COSTA, N. R. et al. Demandas populares, políticas públicas e saúde. Petrópolis, Vozes, 1989, Vol. 2, p.145-64.

RAMOS, C. L. et al. Introdução. In: Costa, N. R. et al. Demandas populares, politicas públicas e saúde. Petrópolis, Vozes, 1989, Vol. 2, p.7-12.

REZENDE, A. L. M. Saúde: dialética do pensar e do fazer. São Paulo, Cortez, 1989. 
RIVERA, F. J. U. org. Planejamento e programação em saúde - um enfoque estratégico. São Paulo, Cortez, 1989. p. 22-55: Planificação em saúde na América Latina: histórico e análise da doutrina e dos enfoques metodológicos.

SADER, E. Quando novos personagens entraram em cena: experiências e lutas dos trabalhadores da Grande São Paulo, 1970-1980. Rio de Janeiro, Paz e Terra, 1988. p. 25-60: Idéias e questões.

SMEKE, E. L. Saúde e Democracia: experiência de gestão popular: um estudo de caso. Campinas, 1989. [Tese de Doutorado - UNICAMP]

TAVEIRA, M. Planejamento e programação: aproximações diferenciadas ao problema. Saúde em Debate. (32):38-43,1991.

TEIXEIRA, S. M. F. (org.) Reforma Sanitária: em busca de uma teoria. São Paulo, Cortez/ ABRASCO, 1989. p. 17-46: Reflexões teóricas sobre democracia e Reforma Sanitária.

TESTA, M. O diagnóstico de saúde. In: RIVERA, F. J. U. et al (org.) Planejamento e programação em saúde - um enfoque estratégico. São Paulo, Cortez, 1989. p. 59-76.

\footnotetext{
Summary: The present paper aims at both reflecting upon the citizenship and institutional power and depicting the different perceptions of health held by different social/institutional subjects linked to a basic health unit in order to search for ways of contributing to the consolidation of the National Public Health System (SUS) and thus the Sanitary Reform. In this way the theory of problematization-action was applied to the users of the School Health Centre Jardim Campos Eliseos for the selection of certain actions to solve part of the existing problems. This paper shows the possibility of keeping the counter-hegemonic struggle in search for social equality even in unfavourable scenarios.
}

Key words: right to health; exercise of citizenship; theory of problematization-action; social/institutional perception 